\title{
LA PATAGONIA YA NUNCA SERÍA LA MISMA: DEL MELODRAMA A LA DEFENSA DEL MEDIO AMBIENTE
}

La Patagonia ya nunca sería la misma: from melodrama to the defense of the environment

\author{
Sergio Mansilla Torres*
}

\section{Resumen}

En este trabajo se discute la imagen de la Patagonia -en este caso de aquella zona de Patagonia que corresponde a Aysén- que proyecta la novela La Patagonia ya nunca sería la misma desde la mirada y comportamiento de los personajes protagonistas de la misma. Se estudia en particular el tópico de la naturaleza prístina, la que ejercería una especie de efecto purificador sobre las conductas, actitudes y espiritualidad incluso, de sujetos que en algún momento de sus vidas han sido instrumentos del "progreso" y la industria a costa de la propia naturaleza, como sucede especialmente con el ingeniero Letelier, protagonista masculino de la novela. Esto en el contexto de una lucha contra la eventual instalación de la megarrepresa conocida como HidroAysén en los grandes ríos de la Patagonia Norte.

Palabras clave: Ecopoética, HidroAysén, literatura y medio ambiente, ecocrítica, estética de la naturaleza.

\section{Abstract}

In this essay we discuss the image portrayed of Patagonia -in this case, that area which corresponds to Aysén- that is projected by the novel La Patagonia ya nunca sería la misma from the perspective and behavior of its protagonists. We study specifically the topic of pristine nature, which exerts a type of purifying effect on the conduct, attitude, and even spirituality, of the subjects that, at some point in their lives, have been instruments of "progress" and of industry in detriment of nature itself, as what transpires with the engineer named Letelier, a male protagonist of the novel. This occurs in the context of a battle against the eventual installment of a mega hydroelectric dam, known as HidroAysén, amongst the great rivers of the northern Patagonia.

Key words: Ecopoetics, HidroAysén, literature and environment, ecocriticism, aesthetics of nature.

\section{LA PATAGONIA COMO SANTUARIO}

En 2011 Héctor Ducci Budge publica su novela La Patagonia ya nunca sería la misma (en adelante La Patagonia) en la que se narra la historia del ingeniero hidráulico José Luis Letelier que de trabajar para la empresa HidroAysén pasa a convertirse en activista radicalmente contrario al megaproyecto hidroeléctrico de represar los ríos Baker y Pascua, en la Región de Aysén, Chile, acción proyectada precisamente por 
HidroAysén ${ }^{1}$. La historia de la transformación del protagonista masculino va unida a una historia de amor con una mujer estadounidense, MaryAnne Morris-Davis, quien, tras abandonar su país, se vino a vivir en el Aysén profundo; ella justamente opera como personaje catalizador del cambio de posición de José Luis Letelier. El propósito de este trabajo es trazar una aproximación a la imagen de la Patagonia que proyecta la novela por medio de la mirada y comportamiento de los personajes protagonistas; específicamente, la idea es incursionar en la imagen de la naturaleza patagónica que la novela destila y los efectos de esta naturaleza en personajes que, a su manera, confrontan la ocupación industrial de los espacios naturales todavía ajenos a la intervención humana.

Digamos, para empezar, que la novela insiste en representar una naturaleza primigenia, de prístina belleza, la que, por lo mismo, ejercería un efecto purificador en las conductas, actitudes y aun espiritualidad de sujetos que en algún momento de sus vidas han sido instrumentos del "progreso" y la industria a costa de la propia naturaleza. Ese es el caso del ingeniero Letelier, precisamente. El resultado inmediato es que la novela visualiza a la Patagonia como un espacio utópico, lugar de limpieza espiritual y moral para quienes vienen ya de vuelta de los mundos urbanos hiperpoblados y que se refugian en la solitaria naturaleza patagónica convertida entonces en un santuario que siempre debería estar protegido de los estropicios de la industria y de sus intervenciones modificadoras de los espacios naturales. Un santuario que, en tanto se lo protege, protege a su vez a los espíritus sensibles a las bellezas naturales que anhelan plenitud existencial lejos del "mundanal ruido", héroes silenciosos de una cotidianidad armonizada con la naturaleza y sus ritmos vitales. Hablamos de una sensibilidad algo new age, se podría decir, pacifista y hasta idílica, con resultados trágicos, por desgracia, ya que nuestros personajes migrantes, ecologistas y defensores acérrimos de una Patagonia prístina y virginal, terminan siendo víctimas de manifestantes urbanos descontrolados (en Santiago, la capital). Estos manifestantes se muestran como sujetos citadinos que exhiben una propensión a la violencia y al vandalismo simétricamente contraria a la paz de los bosques y los ríos ayseninos. El protagonismo de José Luis y MaryAnne contrasta con la escasa relevancia de los habitantes nativos de Aysén; se difuminan, la mayoría, en un fondo vago que recuerda las siluetas de cerros y bosques en un atardecer invernal. Y si es que aparecen en primer plano, son personajes situados

\footnotetext{
${ }^{1}$ Se trabajó con una versión digital no paginada de la novela. En relación con el caso de HidroAysén el lector podrá hallar un exhaustivo análisis del mismo desde el punto de vista de la ecología política en "Ecología política y represas: elementos para el análisis del Proyecto HidroAysén en la Patagonia chilena", de Hugo Romero Toledo (2014). En todo caso, el conflicto con HydroAysén vino a poner en evidencia un aspecto crítico del modelo de desarrollo hoy vigente en Chile, que pasa por una exorbitante necesidad de recursos naturales para sustentar una economía esencialmente extractiva, la que por desgracia no ofrece garantías de real desarrollo distributivo y democrático. La opción por el extractivismo a ultranza pareciera conducir a la aniquilación, acaso definitiva, de espacios naturales por la necesidad de hacerse con los recursos de dichos espacios.
} 
en una posición subordinada en relación con los que ahora son ecologistas militantes llegados, además, hace poco a la Patagonia.

"¡La Patagonia! -exclamó- es una amante exigente. Te embruja ¡es una hechicera! Te atrae a sus brazos y nunca te suelta" (Chatwin, 2015). Así es como Bruce Chatwin le hace decir al poeta del río Chubut, personaje circunstancial e innominado de su novela En la Patagonia ${ }^{2}$, en una conversación que en el capítulo 14 de la mencionada obra sostienen Chatwin y el poeta. Viene a cuento la cita de Chatwin porque bien podría considerarse una síntesis de las actitudes y sentimientos que animan a nuestros personajes protagonistas a hacerse patagones por adopción: José Luis quien renuncia a su vida urbana santiaguina y MaryAnne, quien, como se adelantó, dejó su país y se trasladó a vivir a Aysén luego de comprarse un campo "relativamente grande" (Ducci, 2011, cap. 6). MaryAnne es, además y desde el principio, una defensora del medio ambiente natural y se opone frontalmente a la construcción de las represas proyectadas por Hidroaysén. Ambos de una edad aproximada de 50 años, son personajes que en el camino de sus vidas vienen, como se suele decir, ya de vuelta. José Luis se halla virtualmente separado de su familia santiaguina que se niega a seguirlo a las tierras patagónicas; MaryAnne por su lado es viuda, sus hijos ya adultos viven en Estados Unidos y se niegan igualmente a seguirla a las inmensidades patagónicas. Ambos, entonces, seducidos por las tierras australes, yacen atrapados en los brazos de esa amante exigente que se llama Patagonia.

La novela de Ducci es una historia de amor que tiende a sobredimensionar los sentimientos y adelgazar las subjetividades, de manera que estas aparecen delineadas con trazos simples y básicamente determinadas -las subjetividades- por su condición de enamorados. Sin embargo, Ducci, al instalar esta anécdota en un escenario real de conflicto entre la gente patagona aysenina de a pie y una poderosa corporación dedicada a la generación hidroeléctrica, la historia de amor -aunque ficticia- se vuelve una historia inscripta en lo que de un tiempo a esta parte se ha ido convirtiendo en la madre de las batallas de la modernidad: o se es moderno con la naturaleza o contra ella. José Luis, como ya se dijo, de ser funcionario de Hidroaysén pasa a ser ecologista activo en abierta oposición al proyecto industrial que en su momento él mismo contribuyó a delinear mediante numerosos estudios en terreno; MaryAnne, por otro lado, de emigrante que busca, en solitario, la paz de los bosques para vivir, transita igualmente al activismo ecológico en la medida en que con su nueva pareja y amigos emprende una lucha frontal, directa y organizada, contra el proyecto HidroAysén.

La Patagonia sigue el modelo de la novela romántica decimonónica. De hecho, recuerda de cerca a Amalia de José Mármol (1997), pues sobre el cañamazo de una historia de amor se borda un conflicto de alcances colectivos: la cuestión de fondo que la novela de Ducci releva es si se debiera o no permitir la construcción de las represas en

\footnotetext{
${ }^{2}$ Por los datos que el propio Chatwin desliza en su novela, estimo que se trataría del poeta Gonzalo Delfino. Chatwin menciona que el poeta publicó Cantos rodados y Voces de la tierra. En efecto, estos libros fueron publicados en 1940 y 1954 respectivamente por el poeta antes mencionado.
} 
los ríos Baker y Cuervo y asumir, como costos necesarios del progreso, la inundación de vastos terrenos con la consecuente destrucción de ecosistemas y de paisajes de belleza única. Se trata de una situación límite, ante esto los personajes protagonistas se ven impelidos a tomar posiciones; MaryAnne, como se adelantó, es desde el principio una opositora radical al proyecto de las represas, si bien su activismo se concretizará luego de la consolidación de su relación amorosa con José Luis. Este, a su vez, vive al inicio una etapa de lealtades encontradas hasta que finalmente se decanta por la misma posición de MaryAnne. Como en la novela de José Mármol (1997) en la que el idilio entre Amalia y Eduardo Belgrano da paso a un vasto cuadro político-social de la larga dictadura de Rosas, en La Patagonia el idilio entre José Luis y MaryAnne es el recurso que permite el despliegue narrativo e informativo de uno de los conflictos ambientales más emblemáticos de los últimos años en Chile: el suscitado por el de HidroAysén al que se oponen (o se opusieron) fervorosamente una parte de la población de Aysén, además intelectuales y ecologistas chilenos y extranjeros ${ }^{3}$. La novela dibuja, en suma, un conflicto entre un modelo de desarrollo capitalista erigido contra natura y una visión de vida en armonía con la naturaleza, representada sobre todo por el personaje MaryAnne, visión que colisiona con una idea de progreso o desarrollo concebida y manejada exclusivamente por grandes corporaciones.

Es en la trama de episodios novelescos y en las consecuentes referencias al conflicto suscitado por HidroAysén donde aparece la cuestión del paisaje patagónico. $\mathrm{Al}$ respecto, es significativo el viaje que la pareja realiza a Río Pascua; se trata de un verdadero viaje iniciático que abrirá la puerta a la conversión definitiva de José Luis. ${ }^{4}$ Prevalece, en este punto, una imagen mistificada y salvífica de la naturaleza patagónica tanto que redime a personajes como José Luis Letelier, antes un ingeniero hidráulico

\footnotetext{
${ }^{3} \mathrm{Al}$ momento de escribir este trabajo, el proyecto HidroAysén se encuentra detenido por decisión de la propia empresa ante lo que sus directivos califican como una situación de incertidumbre y trabas para desarrollar el proyecto de generación eléctrica: "considerando que en la actual situación en que se encuentra el proyecto (la revocación de la RCA [Resolución de Calificación Ambiental] de mayo de 2014 fue recurrida ante los tribunales ambientales de Santiago y Valdivia) existe incertidumbre acerca de la recuperación de la inversión realizada, ya que esta depende tanto de decisiones judiciales como de definiciones respecto de materias de la Agenda de Energía que actualmente la compañía no está en condiciones de prever. Al mismo tiempo, HidroAysén no se encuentra (en) el portafolio de proyectos inmediatos de la compañía”. Declaración del Directorio recogida en el medio digital La Nación el 29 de enero de 2015, además de varios otros medios informativos. Para muchos, esto ha sido considerado un triunfo legítimo de los ecologistas, pero, para otros, es la expresión ganadora de un extremismo ecologista que tendrá serias consecuencias para satisfacer las futuras necesidades de energía. Como sea, semejante decisión es un indicador de cambio político y cultural en Chile no precisamente favorables a la irrupción inconsulta de las grandes corporaciones en territorios periféricos, aun si las razones técnicas fuesen óptimas y pertinentes. La ocupación o intervención de territorios para utilizarlos como fuentes de energía se ha vuelto en el Chile actual una fuente de conflictos políticos, culturales y territoriales que desbordan de lejos consideraciones meramente económicas.

${ }^{4}$ Ver capítulos 13 y 14 de la novela. La pareja, aunque todavía no consolidada como tal en términos amorosos, llega hasta el mismo punto en que HidroAysén proyecta construir la represa Pascua 2.2. La contemplación de la belleza paisajística y el diálogo que sostienen José Luis y MaryAnne termina por inclinar la balanza a favor de la naturaleza, contra HidroAysén, de parte de José Luis.
} 
que trabajó para represar los ríos de la Patagonia, ahora un defensor acérrimo de los mismos. La novela le otorga a la naturaleza patagónica un poder de conversión lo suficientemente grande como para ejercer sobre José Luis un efecto similar al que sufrió Saulo en su camino a Damasco: de perseguidor de cristianos a cristiano radicalmente comprometido con su nueva afiliación. José Luis Letelier vive su propio camino a Damasco en Aysén. Cierto que la relación amorosa con MaryAnne contribuye al cambio de posición, pero MaryAnne viene solo a ser el factor desencadenante de un proceso cuya causa última es la relación de plenitud existencial, estética y ética que consigue establecer José Luis con el paisaje natural de la Patagonia.

Porque Letelier, ya antes de conocer a MaryAnne, venía siendo afectado por dudas. Su permanencia en la Patagonia no obedece sino a razones pragmáticas: por trabajo, en primer lugar (es reconocido como un importante ingeniero por sus empleadores y sus pares); también por escapar de una ambigua situación familiar que se manifiesta en un creciente distanciamiento con los suyos. En los hechos se halla separado de su esposa y sus hijos quienes no están dispuestos a dejar Santiago de Chile, menos si es para trasladarse a un territorio que les resulta aburrido, indiferente; carecen de ojos y oídos para percibir la belleza paisajística que sí ve y oye José Luis. Hay entre este personaje y su familia un abismo infranqueable en el que vienen a situarse justamente la prístina naturaleza patagónica y MaryAnne, ambas cierran la brecha afectiva de este ingeniero.

El caso de MaryAnne es un poco diferente. ¿Qué hace una ciudadana estadounidense en Aysén? La novela la muestra como un personaje práctico, habita una muy confortable casa en el campo aysenino dotada de calefacción central, internet; dispone y disfruta de la buena comida y del buen trago, si bien de un modo frugal. Cuenta con movilización propia, con servicio doméstico; sabe trabajar la tierra, tratar con los animales domésticos, de buen gusto estético, se desenvuelve con solvencia en español; es una ecologista convencida -más todavía después del viaje a Río Pascua-. Diríamos, una perfecta "progresista" internacional de los tiempos de la globalización, cariñosa y muy femenina por añadidura; un personaje que representa, me parece, a muchos habitantes del llamado Primer Mundo, quienes, sobresaturados de modernidad, de consumismo, hartos de la vida "postnatural" de las grandes urbes, emigran a territorios en los que la naturaleza es todavía la gran protagonista de la cotidianidad. Visto así, su oposición al proyecto hidroeléctrico es, al mismo tiempo, la defensa de su propio proyecto de vida existencialmente ligado a la sublime naturaleza patagónica. Quizás entonces -y a diferencia de lo que sugiere el poeta, me refiero al personaje de Chatwin- el hechizo patagónico no es, no tiene que ser, opresivo, trágico, devastador. En el relato de Chatwin el poeta ya no es poeta en realidad: "el poema puede esperar", dice, repitiendo a Eliot, pero la cita es una manera de encubrir y acaso justificar su propia decadencia en una habitación oscura y descuidada en la que transcurren sus días rodeado de libros polvorientos. La precaria cabaña del poeta contrasta con la luminosa, limpia y bien abastecida casa de MaryAnne. 
Sergio Mansilla Torres

PATAGONIA: SILVESTRE Y FRÁGIL

Me parece que aquí hay un punto importante en el que convendría poner atención. Ducci elabora una imagen del paisaje patagónico, de la zona de Aysén en este caso, que, aun con su desmesura y sublime belleza, no toma la forma de un espacio trágico, bárbaro, hostil, en el que los sujetos quedan expuestos a experiencias límites de soledad o de violencia, como sucede en buena parte de la literatura patagónica contemporánea, desde Coloane hasta ahora. Ducci, en cambio, nos instala en una Patagonia que recuerda el locus amoenus de la literatura latina, si bien este locus dista bastante de exhibir los clásicos atributos de los entornos europeos mediterráneos que subyacen bajo la fantasía literaria del locus amoenus europeo. Lo que Ducci subraya, mediante la estrategia de representar la naturaleza como excepcionalmente bella y amena, no obstante su fuerza telúrica (o acaso por eso mismo), es la idea de que la irrupción de la hidroeléctrica que pretende represar ríos todavía vírgenes, constituiría -si se construyesen esas represas, se entiende- un crimen ecológico y estético de lesa humanidad que debe ser detenido antes de concretarse.

La convicción que subyace aquí es que la naturaleza, por más grandiosa que sea, siempre es una potencial víctima de la intervención humana. Aunque no de cualquier intervención desde luego sino de aquellas realizadas por grandes corporaciones, las que con su personal técnico, con su tecnología, su capital prácticamente ilimitado y sus discursos prometedores de bienestar y trabajo (a lo que habría que sumar acciones de asistencialismo menor) terminan por aparecer como felices y providenciales oportunidades para el desarrollo de una región determinada ${ }^{5}$. La novela de Ducci, muy lejos de la corriente mundonovista latinoamericana que en los años de 1920-30 dibujó una imagen de naturaleza hostil, bárbara, hasta tenebrosa, que se vengaba de la codicia e impiedad humana, nos instala en la escena de una naturaleza indefensa, objeto de posible intervención masiva, algo que acabaría para siempre con paisajes que han estado ahí quizás por millones de años.

Le corresponde, entonces, a los humanos defender los entornos naturales no intervenidos. MaryAnne explica sus razones por las que se opone a HidroAysén, las que sintetizan los argumentos que esgrimen quienes son contrarios a la represas en cuestión. Dice el narrador:

\footnotetext{
${ }^{5}$ De hecho, en el capítulo 12 MaryAnne polemiza con la columna 'U. S. Greens vs. Chile's Poor", publicada en 2011, escrita por Mary Anastasia O'Grady, editorialista de The Wall Street Journal, quien en dicho medio plantea que la oposición al proyecto HidroAysén es, en realidad, una confrontación entre ecologistas acomodados y los planes del gobierno chileno, entonces presidido por Sebastián Piñera, destinados a crear riqueza y desarrollo, para lo que se necesita mucha energía para hacer andar las nuevas industrias, riqueza y desarrollo que terminará beneficiando a los pobres. El 12 de julio de 2011 el diario El Mercurio, de Santiago de Chile, publicó la versión en español de la columna de O'Grady bajo el título 'Los ambientalistas de USA vs. los pobres de Chile". Al momento de redactar este trabajo (agosto 2016) ya no se halla disponible esta columna, en su versión en inglés, en el sitio The Wall Street Journal; pero sí en español en varios sitios (se indica en la bibliografia el sitio web utilizado en esta oportunidad). Volveré más adelante respecto de algunas de las tesis planteadas por O'Grady.
} 


\section{La Patagonia ya nunca sería la misma: del melodrama a la defensa del medio ambiente}

Se oponía a HidroAysén por múltiples razones. Mencionaba la inundación de áreas de irrecuperable belleza, los cambios que experimentaban los ríos aguas debajo de las represas, el embancamiento de las mismas, la deforestación que causaban las obras civiles, la enorme cantidad de gente que llegaría a la zona con los consiguientes problemas de movilización, hospedaje, alimentación, aumento del costo de vida para los lugareños y eventual criminalidad y prostitución. Le preocupaba sobremanera el daño ecológico que provocaría la línea de transmisión de 2800 kilómetros de longitud y de cien metros de ancho, que dejaría una enorme herida en el territorio, a la cual se accedería por un sinfin de caminos que tendrían que construirse para llegar con sus componentes hasta los lugares designados para la ubicación de las enormes torres [...] Pero lo que más le preocupaba era [...] el trastorno total del estilo y calidad de vida [de la gente de Aysén] por al menos doce años, y luego un destino y un futuro tal vez semejante al que ahora experimentaba Ralco, convertida post-construcción de la represa en la comuna más pobre y con mayor cesantía del país (Ducci, 2011, cap. 7) 6 .

José Luis, por su lado, al menos hasta antes de que comience su cambio de posición, esgrime argumentos a favor de HidroAysén que, en lo esencial, son los mismos que la empresa involucrada expone ante el gobierno y la ciudadanía:

Los requerimientos energéticos del país se conocen desde hace muchos años... Un paréntesis. Parece increíble, pero ya en 1892 el Presidente Diego Barros Arana (sic) solicitó al doctor Hans Steffen que dirigiera una expedición que incluyó a los ríos Baker y Pascua. Al parecer, desde hace más de un siglo, ya le tenían echado el ojo a estos ríos [...] Es verdad que el proyecto afecta a una zona remota del país, en que vive poca gente a una zona remota del país, en que vive poca gente y que una vez en funcionamiento aportará 2750 megawatts al sistema [...] Chile es un país pobre. Si lo queremos ver desarrollado y sobre todo más equitativo, necesitamos energía. No tenemos gas ni petróleo, nos queda poco carbón, debemos comprarlo y a precios cada vez más altos [...] el agua es nuestra, está ahí, en regiones muy poco visitadas (Ducci, 2011, cap. 7) ${ }^{7}$.

Letelier, con menos convicción que MaryAnne, arguye, en última instancia, a favor de un modelo de desarrollo basado en el uso masivo e intensivo de recursos naturales ubicados en lugares específicos aun al precio de tener que intervenir los espacios naturales de esos lugares haciéndolos desaparecer, o modificándolos cuando

\footnotetext{
${ }^{6}$ La central hidroeléctrica de Ralco, emplazada en el Alto Biobío, en la zona sur de Chile, es de propiedad de Endesa. Ese proyecto, autorizado en 1998 durante el gobierno de Eduardo Frei Ruiz-Tagle, e inaugurado durante la presidencia de Ricardo Lagos Escobar, es actualmente una de las centrales hidroeléctricas más importantes de Chile, aportando algo así como 10\% de la generación de energía. Su construcción no estuvo libre de problemas debido a un conflicto con los pueblos indígenas pehuenches que habitan el Alto Biobío. Remito al lector interesado al reportaje "Chile: Ralco le cambió la vida a los pehuenches" (web).

${ }^{7}$ Diego Barros Arana (1830-1907), historiador, intelectual, nunca fue Presidente de Chile. En 1892 el Presidente era Jorge Montt Álvarez, quien nombró a Barros Arana rector de la Universidad de Chile. La referencia a Steffen, un geógrafo alemán contratado por el gobierno de Chile, es auténtica. Recorrió la Patagonia entre 1892 y 1899.
} 


\section{Sergio Mansilla Torres}

menos, para siempre. Este argumento será expuesto con más detalles, con un formato técnico (con datos estadísticos), en el episodio en que el presidente de HidroAysén expone ante la comunidad local el proyecto de inversión empresarial y las razones y propósitos que lo animan. En lo esencial del presidente de la empresa el argumento se basa en sostener que cumplen rigurosamente con la normativa correspondiente (si las leyes no son buenas o no, es un asunto respecto del que no le corresponde pronunciarse) y que producir más energía eléctrica es indispensable para asegurar el desarrollo del país. Ciertamente, la modificación del entorno natural es un efecto imposible de eludir si lo que se va a instalar es una megaempresa como HidroAysén (ver cap. 21). Al respecto, lo que sugiere el argumento del presidente de HidroAysén es que la preservación de los paisajes naturales por razones estéticas es un lujo que un país todavía pobre y falto de desarrollo como Chile no se puede dar. No es, sin embargo, lo que sostiene MaryAnne.

\section{EL ARGUMENTO ESTÉTICO}

MaryAnne en el capítulo 14 de la novela apela justamente al argumento estético para defender los ríos que serían represados por HidroAysén:

Dime, José Luis, pese a las consideraciones económicas y las necesidades energéticas de Chile, ¿no es la belleza de estos lugares un argumento poderoso para no hacer las represas? ¿Tú crees que alguien aceptaría echar abajo la Capilla Sixtina, o el Taj Mahal, el palacio de Topkapi o un trozo de la Muralla China porque la utilización de estos lugares con otro destino sería más rentable? No digo nada nuevo cuando te aseguro que hay pocos lugares en el mundo con esta belleza. Si se ha definido la belleza como algo que causa placer, algo que agrada a la vista, ¿qué más placer, qué más agradable vista puede ser el lugar en que estamos?, ¿y lo vamos a borrar en pro de más energía? ¿Y desde cuando los humanos tenemos esos derechos? Estamos locos... (Ducci, 2011,cap. 14).

El argumento de MaryAnne suena, en principio al menos, impecable si atendemos a la singularidad y magnificencia de los paisajes de los ríos Baker y Pascua. La novela, ciertamente, pone en escena dos visiones contrapuestas acerca de la naturaleza. Una -la defendida por MaryAnne- es aquella que pretende preservarla a toda costa gracias a su singularidad ecológica y estética. Aunque MaryAnne es contraria a la llamada "ecología profunda": "Había leído - dice el narrador- a Arne Naess, el noruego que parecía el gurú de Tompkins y consideraba su posición -que definía la ecología profunda como un movimiento según el cual se hace el bien no por el interés humano sino por el bien del planeta- muy extrema" (Ducci, 2011, cap. 7) ${ }^{8}$. Como fuere,

\footnotetext{
${ }^{8}$ Douglas Tompkins (1943-2015), ciudadano estadounidense, multimillonario y ecologista. Vivió 25 años en Chile y en vida adquirió extensos bosques nativos en la zona de Palena, Chile, que hoy tienen el estatus legal de santuarios de la naturaleza o de parques nacionales. Su labor fue, en su momento, muy criticada por sectores nacionalistas (veían en las adquisiciones una especie de ocupación territorial extranjera) o ligados a la industria de la madera. Sus radicales planteamientos en defensa de la "ecología profunda" lo hacían contrario a la 40
} 
MaryAnne es conservacionista y no puede comprender que paisajes de belleza única sean sacrificados en beneficio de la economía.

En la orilla opuesta está el argumento propiamente económico: se necesita más energía, y en ingentes cantidades; producirla aprovechando la fuerza motriz de los grandes ríos patagónicos es factible, económicamente conveniente además. $\mathrm{Al}$ respecto, en el capítulo 21 el novelista hace hablar al presidente de HidroAysén en una conferencia pública ante la comunidad de Coyhaique:

Los estudios del gobierno y de entes privados, todos llevados a cabo por conocidos ingenieros, indican que para 2020 Chile necesita 12000 megawatts adicionales. El 73\% de la Región Metropolitana y el 70\% de la Región de Aysén están de acuerdo en que Chile tiene un problema energético y que se requiere de inversiones e infraestructura para aumentar la matriz de las fuentes de energía. $\mathrm{Si}$ eso no se hace, Chile no crecerá al ritmo que necesita hacerlo para alcanzar el desarrollo. Cada empresa mayor, cada Pyme que se cree a partir de hoy, requerirá energía con la que no contamos. Es por esto la urgencia de hacerlo... El megawatt producido con energía sola fotovoltaica cuesta, de acuerdo con nuestros cálculos, 360 dólares, con energía eólica 100, mientras que con HidroAysén solo 40. Y el agua es nuestra, está ahí, en nuestros ríos, y la energía derivada de las aguas es la más barata, siendo la generada por diesel la más cara (Ducci, 2011).

En efecto, estamos ante dos lógicas muy diferentes y en última instancia incompatibles. Así planteadas las cosas, la novela nos lleva a un intríngulis cuya salida, si es que la hubiere, podría ser trágica en tanto se trata de visiones de mundo -y de prácticas de modernización- inconciliables y en colisión frontal. José Luis, ya convertido en activista, viaja a Santiago a participar en una manifestación "pacífica" que resultó de mayor convocatoria que la esperada y que, por lo mismo, dio paso a la participación violenta de "encapuchados"'. Precisamente entre estos y fuerzas policiales (carabineros) se produjo un incidente serio, tanto que un policía, al quedar aislado de sus compañeros, comenzó a recibir un castigo violento de parte de encapuchados. José Luis, movido por el recuerdo de los policías de la Patagonia, que lo habían socorrido en más de una ocasión, se lanza en ayuda del carabinero; en la refriega estalla una bomba molotov, cae inconsciente y termina con el $60 \%$ de su cuerpo quemado. Sus posibilidades de sobrevida son escasas, tan escasas como las de los ríos y bosques patagónicos que han escapado hasta ahora de la devastación permanezcan intocados, o sea, vivos. La extrema vulnerabilidad del cuerpo quemado de José Luis simbólicamente alude, me parece, también a la extrema vulnerabilidad del medio ambiente natural

decimonónica tesis de que poblar territorios despoblados es condición de base para asegurar el progreso y soberanía de la nación. La noción de "ecología profunda" fue acuñada en 1973 por Arne Naees, filósofo noruego (1912-2009).

${ }^{9}$ Término que se aplica a manifestantes, usualmente violentos, que se cubren el rostro con pasamontañas, pañuelos o capuchas con el fin de no ser reconocidos por la policía. Suelen actuar en el marco de manifestaciones masivas motivadas por causas diversas. 
patagónico, ya quemado en la gran parte por los enormes incendios de años 40 del siglo XX. Desde luego, si se represan los ríos, se talan los bosques, se dinamitan acantilados, se inundan valles, "la Patagonia ya nunca sería la misma", afirmación con la que se clausura el libro de Ducci, y que es, al mismo tiempo, el título de la novela.

Convengamos que la anécdota amorosa no ofrece sorpresas, que los personajes protagonistas son relativamente estáticos y hasta cierto punto previsibles, que se encuadran sin más dentro del arquetipo del ecologista educado, de clase media alta, con conciencia crítica respecto del modelo de desarrollo basado en la sola acumulación de riquezas, con apego a la naturaleza, refractario a las ciudades, que se han provisto de una identidad ecologista tras un largo camino de aprendizaje y de transformación psíquica. Sin perjuicio de esto la novela tiene el mérito de escenificar un momento crucial para la civilización tecnológica occidental; la misma que está llegando, o ya llegó según se mire, a límites infranqueables con la naturaleza, tanto que si se rebasan esos límites entraremos, si es que ya no entramos, a la entropía de nuestra civilización. Lo crucial y lo trágico estriba en que los centros de poder de nuestra sociedad moderna industrial parecieran ignorar las señales que hablan de un riesgo alto de que nuestro planeta, o parte importante de él, se vuelva incompatible con la vida humana, por razones no atribuibles exclusivamente a la naturaleza claro está. De cualquier modo, si HidroAysén cede en sus propósitos, no cederá por otra cosa que no sea arribar a la convicción de que construir las represas y las líneas de transmisión es un mal negocio (aunque más por razones políticas que económicas); ${ }^{10}$ en sus planes no cuentan en absoluto los argumentos estéticos o ecológicos si de modificar sitios se trata para los fines empresariales que les son propios.

Por lo mismo, la cuestión de fondo que podemos derivar de la novela no es si vale la pena o no defender un río o un bosque determinado para mantenerlo en estado puro o, en su defecto, alinearse con la industria y dar al traste con esa naturaleza particular en estado virginal. Mantener(se) en este dilema quizás no haga otra cosa que reforzar la prevalencia de lo que ya ha venido aconteciendo desde los tiempos de la Revolución Industrial en adelante: el poder laminador de la civilización industrial tecnológica, ejercido por gobiernos o, como sucede ahora, por corporaciones trasnacionales poderosísimas, empuja a sus detractores ecologistas a que queden atrapados en el estereotipo de minorías más o menos "románticas", utopistas, que han llegado a abrazar un rol subversivo en defensa de su propio bienestar o en defensa de una idealidad impracticable en la realidad material (producción y consumo) del mundo moderno.

Este dilema, a mi parecer, abona el terreno para que los ecologistas terminen siendo (o sean vistos como) minorías acomodadas más o menos incapaces de entender, pero sobre todo de aceptar, que la modernidad, que permite el bienestar, la seguridad, el acceso a la tecnología para diversos fines, etc., en su dimensión infraestructural y tecnológica al menos, no puede construirse sino modificando el ambiente y los territorios (las ciudades, las vías de comunicación, son dos ejemplos palmarios). La modernidad necesita de infraestructura y de

${ }^{10}$ De hecho, así es como HidroAysén justifica la suspensión del proyecto. 
tecnología, y crearlas y construirlas requiere de capitales y de empresas que hagan el trabajo de remover lo que haya que remover, edificar los que haya que edificar aun a costa de transformar/destruir paisajes únicos. Oponerse a esta forma de proceder con argumentos que apelan a la belleza paisajística viene a ser problemático, pues, por ejemplo, contra el argumento estético de MaryAnne se podría decir que los bosques de la Patagonia, sus ríos, no son equivalentes a la Capilla Sixtina o al Taj Mahal, pues no son obras propiamente humanas, y no se ve en los bosques ni el talento ni la grandiosidad de artista humano alguno. A lo que se podría añadir que ni la Capilla Sixtina ni el Taj Mahal son propiamente sitios para vivir (son sitios para visitar, contemplar y maravillarse de la grandeza humana), de modo que si estas edificaciones fueran de veras equivalentes a los bosques y ríos patagónicos, estos -los bosques y ríos- tampoco serían sitios para vivir con habitantes instalados ahí: solo lugares para visitar, contemplar y maravillarse de las bellezas naturales (que es lo que de hecho hacen nuestros protagonistas). Pero los humanos necesitamos lugares para vivir, no solo para contemplarlos extasiados.

\section{NATURALEZA VS. INDUSTRIA: ¿UNA CONFRONTACIÓN SIN SALIDA?}

Un poco provocativamente podríamos argüir, entonces, que los ecologistas, en especial los del primer mundo o de las elites metropolitanas, nunca llegarán a entender del todo que en sociedades precarizadas, en las que un sector a veces mayoritario de la población no tiene certeza de poder comer al día siguiente (no es el caso de Aysén, sin embargo), ser ecologista es un lujo que muy pocos se pueden dar, al menos ecologistas como los que son representados por MaryAnne y José Luis. En este terreno, la novela escenifica el dilema entre elegir la naturaleza o la industria en un devenir excluyente que se endilga lamentablemente hacia un camino trágico. La eventual muerte de José Luis es evidencia de un impasse que por ahora carece de solución, salvo confiar en el milagro casi sobrenatural de su recuperación y, en consecuencia, confiar en que, por una feliz coincidencia de voluntades, las represas finalmente no se construyan. Sin embargo, implícitamente y ante este dilema, la novela también propone un reto: la tarea que aguarda a escritores, filósofos, cientistas sociales que se ocupan de los modos de habitar sustentables, no ha de ser simplemente insistir en la contraposición irreductible entre la idea de un mundo "real" en que naturaleza e industria irremediablemente colisionan porque de otro modo no habría desarrollo económico y la de un mundo "ideal", deseado, soñado, en el que reine armonía entre orden natural y orden culturaleconómico. Porque mientras permanezca activo el dilema en los términos en que lo plantean MaryAnne y el gerente de HidroAysén las corporaciones llevan las de ganar, por más que pierdan algunas importantes batallas, en la medida en que se les pavimenta el camino a prácticas de populismo empresarial. Y si ganan las corporaciones, ya sabemos que se adelgazará un poco más la biodiversidad del planeta.

Populismo empresarial es lo que anima los argumentos de Mary O'Grady en The Wall Street Journal. El conflicto entre naturaleza e industria suscitado por el proyecto HidroAysén, O'Grady lo hace ver como una instancia de lucha de clases 
invertida: son los ecologistas ricos, estadounidenses por añadidura (imperialistas, digamos), quienes impedirían a los chilenos pobres salir de su pobreza con el argumento de defender una naturaleza prístina, que no sería si no aquella con la que estos ecologistas satisfacen sus sofisticadas necesidades de mundo natural. Sabido es que la Patagonia, sus bosques y canales, suele ser destino predilecto de un turismo de alta gama, y si a esto le sumamos la compra de extensos territorios patagónicos de parte de acaudalados extranjeros con el fin de preservarlos intocados (paradigmático es el caso de Douglas Tompkin), tendríamos que reconocer que existen elementos de base susceptibles de ser movilizados para la construcción de un discurso que arremete contra visiones ecológicas conservacionistas:

Chile es un país pequeño -asevera O'Grady-, pero esta polémica [se refiere al debate acerca de aprobación o rechazo del proyecto de HidroAysén] le ha dado un protagonismo desmesurado, transformándolo en el microcosmos de una batalla mundial mucho más amplia: la que enfrenta a cómodas elites satisfechas con el desarrollo económico existente y quienes se esfuerzan por reducir la pobreza. Provistos de abultadas billeteras, tales grupos internacionales de presión medioambientalista han arrinconado a los combatientes de la pobreza, colocándolos a la defensiva (web).

De que el argumento de O'Grady puede ser rebatido en más de un punto, no cabe duda alguna. Bastaría con preguntar: ¿debido a la realidad chilena actual en materia de orden económico, quién, siendo conocedor de ella, podría asegurar que HidroAysén es un "combatiente de la pobreza"? La clase empresarial chilena y extranjera avecindada en Chile, con rarísimas excepciones, no se ha caracterizado precisamente por su sentido de solidaridad social; solo es cosa de revisar la historia desde 1820 para acá y los hechos saltan a la vista. MaryAnne expone su propio contraargumento: O'Grady cometería el error de trivializar a los opositores de HidroAysén en tanto la confrontación la reduce a una batalla "épica" que ni de lejos recoge la variedad de razones que impulsan a oponerse al proyecto de las represas y de los muchos sectores sociales que ni remotamente pertenecen a la elite ecologista mundial, que han llegado a ser furibundos opositores al megaproyecto hidroeléctrico. Ella misma se opone porque ama la belleza de los paisajes de los ríos que irían a ser represados, porque quiere que se preserven espacios de naturaleza no intervenida para generaciones futuras, porque las necesidades energéticas sí podrían resolverse por medios menos invasivos (ver cap. 12).

Más allá de que el novelista, mediante sus personajes y del narrador, tome partido contra HidroAysén, el relato reduce la confrontación a una batalla épica entre ecologistas sensibles a la naturaleza, que han hecho de la ciudadanía patagona una marca definitoria de su nueva identidad, y una corporación representada en la figura de su gerente que arguye esencialmente razones económicas presentadas con un ropaje altruista de compromiso con el desarrollo del país. José Luis y MaryAnne no son los ecologistas millonarios que describe O'Grady, cierto; pero igualmente la novela no 
alcanza a incorporar la trama colectiva diversa que ha ido dando paso a una nueva forma de ser moderno, cada vez más renuente a aceptar sin más el poder de las transnacionales y cada vez con mayor sentido de defensa de sus lugares de asentamiento. En este punto, Ducci, al igual que O'Grady, se instala en el dilema naturaleza vs. desarrollo, aunque con signo diferente: toma partido a favor de la naturaleza, convertida en significante político por ecologistas de clase media que se enfrentan a la tecnocracia empresarial como si solo en ella radicara la fuente última (y única) de los modos aberrantes de intervención en el orden natural. No hay que ignorar que HidroAysén, como otras muchas grandes corporaciones empresariales, en Chile al menos, elabora y sostiene un proyecto de megarrepresas porque cuenta con un soporte político de largo alcance cuyos efectos son, al fin, la construcción de periferias degradadas al servicio del centro (entiéndase, al servicio de las elites industriales y financieras metropolitanas). A MaryAnne y José Luis, Ducci los presenta (y representa) como defensores a ultranza de los ríos patagónicos en un escenario de defensa y promoción de proyectos individuales de vida: tal es la construcción de un nido de amor en los territorios rurales patagónicos en los que la plenitud existencial y espiritual hallarían al fin domicilio. Vistos así, no le costaría mucho a O'Grady calificarlos de "ecoextremistas", que velan más por su bienestar personal que por "los pobres de Chile", más todavía si la novela prácticamente no considera personajes de las clases populares salvo como obedientes sujetos de servicio doméstico (en casa de MaryAnne). A esto me refiero cuando afirmo que La Patagonia plantea el dilema naturaleza vs. desarrollo-industria como una instancia de confrontación en la que se abona el terreno para el éxito de la persuasión política proempresarial a partir de un discurso que se rodea de un aura "revolucionaria" promodernidad o que se presenta, cuando menos, como expresión de compromiso moralmente inatacable con las clases postergadas (como el argumento que desarrolla Mary O'Grady).

En el campo literario ya llevamos un buen rato dibujando una enconada y trágica confrontación entre la naturaleza y la modernidad (ciudades, industria, tecnologías). Desde los tiempos de John Clare (1793-1864), el poeta campesino inglés romántico -pero cuya poesía confrontada con la industria excede al romanticismo- y que terminó con la mente trastornada acaso por la imposibilidad absoluta de adaptarse a la modernidad industrial y tecnológica; digo, desde entonces el alegato literario contra la modernidad industrial no ha cesado. La crítica ha sido contra esa modernidad, la nuestra, cuyo ADN cultural pareciera que se encamina en línea recta hacia un estado de "postnaturaleza" si es que no es de lleno hacia el fin mismo de la vida humana así como la conocemos hoy. La tarea crítica y su derivación política y cultural que nos aguarda - a la que la novela nos empuja- pasa nada menos que por erradicar el antropocentrismo soberbio y suicida, que da pie al desprecio o a la indiferencia hacia el mundo no humano, y elaborar, en su lugar, poderosas imágenes de nuestras vidas en las que la actual separación entre cultura y naturaleza carezca de sentido y deje finalmente de existir. ¿Cómo pensar, representar, narrar este necesario giro 


\section{Sergio Mansilla Torres}

hacia el descentramiento de lo humano sin que lo humano pierda su aura de singularidad humana justamente? No tengo respuesta ${ }^{11}$.

Leída la novela en relación con este impasse civilizatorio, habría sí que reconocer que, melodramáticos y todo, José Luis y MaryAnne son la expresión de una insatisfacción muy real, muy justificada, ante una sociedad gobernada por corporaciones cuyo objetivo último es el control absoluto de los servicios estratégicos para el sostenimiento de la vida moderna (energía, alimentación, por ejemplo), sin más consideraciones que los réditos que podrían obtener; prácticas de dominación recubiertas, claro está, de una caparazón discursiva funcional a la idea de progreso, de desarrollo, de bienestar. La novela se podría leer, entonces, como una invitación a pensar lo que falta: bien que del melodrama amoroso se llegue a la defensa de la naturaleza; más todavía si en este empeño la geografia aparece en primer plano, cuestión esencial para sostener una imaginación a contrapelo de un capitalismo al que la singularidad cultural-geográfica de los territorios le importa nada salvo por los recursos ahí disponibles. Pero nada bien que la naturaleza devenga fetiche estético defendido a ultranza por unos medioambientalistas que tienen sus necesidades fundamentales todas resueltas.

Mas, seamos justos también con nuestros personajes: que una extranjera defienda el territorio chileno de la depredación ¿por qué no?, mejor todavía si es estadounidense en tanto connota un movimiento contrario a las históricas prácticas imperialistas de Estados Unidos hacia América Latina, empezando por la guerra expansionista de Estados Unidos contra México entre 1846 y 1848. Que un ingeniero del lado de HidroAysén se pase al bando opuesto, así no sea por razones amorosas, no deja de ser una parábola de mensaje potente. Lo malo es que en la realidad la mayoría de las veces el camino a Damasco va en sentido contrario al de José Luis Letelier. Indagar en ese camino inverso, evidenciar sus nódulos de poder, comprender sus intríngulis hegemónicos, es parte de la tarea que los ríos y los bosques patagónicos nos piden a gritos. La Patagonia, como otros muchos lugares del Tercer Mundo, es una tierra saturada de traumas de conquista y la naturaleza, las geografias han sido el primer campo de feroz lucha. Y, como sugiere Édouard Glissant, en la naturaleza se guardan las intraducibles huellas de una historia de luchas de las que ya no quedan testigos. ${ }^{12}$ No hay, no debiera haber, entonces, lugar para miradas pastorales en que la historicidad radical venga a ser sustituida por la insistente representación de entornos paisajísticos de belleza deslumbrante cuya defensa, sin embargo, pudiera carecer de viabilidad política: una escena que se clausuraría como un nudo ciego, indesatable, de nuestra modernidad.

\footnotetext{
${ }^{11}$ Entiéndase: en el contexto de la novela. Ciertamente existen maneras de ver la relación humanidad-naturaleza que no quedan atrapadas en el dilema de tener que elegir, excluyentemente, entre la industria o la naturaleza; la filosofia y movimiento de la "ecología profunda" es una de ellas. Cosmovisiones indígenas latinoamericanas proveen igualmente de valiosas herramientas teóricas y prácticas para reconfigurar la matriz civilizatoria de Occidente; por ejemplo, los principios del buen vivir o Sumak Kawsay, recogidos actualmente en la Constitución Política de Ecuador.

${ }^{12}$ En este punto sigo de cerca el comentario de Elizabeth DeLoughrey y George Handley (2011) en su introducción a Postcolonial Ecologies.
} 
La Patagonia ya nunca sería la misma: del melodrama a la defensa del medio ambiente

Universidad Austral de Chile* Facultad de Filosofia y Humanidades Instituto de Lingüistica y Literatura Campus isla Teja, Valdivia (Chile) sergio.mansilla@uach.cl

Este trabajo forma parte de la ejecución del proyecto internacional de investigación Red Temática "Cambio transnacional, desigualdad social, intercambio cultural y manifestaciones estéticas: el ejemplo de Patagonia (2015-2018)", encabezado por la Friedrich Schiller Universität, Jena, Alemania, con el concurso de las siguientes universidades: Universidad de Chile, Universidad de Concepción, Universidad Católica de Temuco, Universidad Austral de Chile (Chile), Universidad de Buenos Aires, Universidad Nacional del Comahue, Universidad Nacional de la Patagonia San Juan Bosco (Argentina).

\section{OBRAS CITADAS}

Chatwin, Bruce (2015). En la Patagonia. Trad. Eduardo Goligorsky. Editor Digital: Titivillus. (ebook).

DeLoughrey, Elizabeth \& George Handley, eds. (2011). "Introduction: Toward an Aesthetics of the Earth". Postcolonial Ecologies. Literatures of the Environment. New York: Oxford University Press, 3-39.

Ducci Budge, Héctor (2011). La Patagonia ya nunca sería la misma. Santiago de Chile: Andros Impresores. (ebook).

Figueroa Fagandini, Felipe (2016). "Chile: Ralco le cambió la vida a los pehuenches". En: https://www.veoverde.com/2011/05/ralco-le-cambio-la-vida-a-los-pehuenches/ [24-6-2016].

La Nación (2016). "Endesa decide detener proyectos HidroAysén y Punta Alcalde". Nota de prensa, 29 de enero de 2015. En: http://www.lanacion.cl/ [12-8-2016].

Mármol, José (1997). Amalia. Buenos Aires: El Elefante Blanco.

O'Grady, Mary (2016). "Los ambientalistas de USA vs. los pobres de Chile". En: http://trastienda-arl.blogspot.cl/2011/07/hidroaysen-iii.html [11-8-2016].

Romero Toledo, Hugo (2014). "Ecología política y represas: elementos para el análisis del Proyecto HidroAysén en la Patagonia chilena". Revista de Geografia Norte Grande, 57, 161-175. 